\title{
Study on the Strengthening of Hospital Internal Control and Externalization Regulating of Hospital Financial Management
}

\author{
Pengcheng $\mathrm{Xu}^{1 \text {, a }}$, Wei Hou ${ }^{2, \mathrm{~b}}$, Zewen Chen ${ }^{3, \mathrm{c}}$ \\ ${ }^{13}$ People's Liberation Army 406 Hospital, Dalian, Liaoning, 116000 \\ ${ }^{2}$ Shenyang Military Region Dalian Sanatorium, Dalian, Liaoning, 116000
}

\begin{abstract}
Keywords: Hospital Internal Control; External Standardization Development; Financial Management
\end{abstract}

\begin{abstract}
With the continuous development of modern medical and health undertakings, the internal control of the hospital, the external standardization of financial management has gradually become the support of various medical and health institutions in the fierce competition in the market to obtain sustainable development of the main work to further improve the hospital internal control, Become the basis of its development. Especially the introduction of the market competition mechanism of the hospital so that it gradually become self-financing, self-management of the main market, and the hospital financial management departments only do a good job of internal control to enhance the level of financial management to meet the economic development and social progress needs. This article analyzes the connotation of financial internal control and the external standard hospital management measures. The purpose of this paper is to create more economic and social value for the hospital and promote the sustainable development of the hospital.
\end{abstract}

\section{Introduction}

As the main participants in the current market competition, the hospital should continuously improve self-management capabilities, in order to compete in the fierce market to enhance self-social and economic benefits. Hospital internal control is an important component of financial management work, only to continuously improve the level of internal control of financial management, to be able to achieve sustainable development.

\section{The Hospital Internal Financial Control Connotation}

The internal financial control of the hospital connotation. Hospital internal financial control on the origin of the financial budget, the implementation of the financial plan and to complete the situation to be controlled, which is cybernetics in the hospital financial activities in the actual use, not that is a simple situation or events, but refers to the hospital financial management The control act carried out by the staff member. From the overall point of view, internal financial control is through the cybernetics approach, the principle of the financial activities of the scientific constraints, norms, evaluation, so as to achieve pre-set goals. The financial accounting information processing process to control, this process includes data processing, input, analysis, output and other different steps. Through the initiative to adjust, control to make any deviation from the financial objectives of the behavior can be corrected, so as to achieve the hospital financial management stage objectives and requirements.

The meaning of hospital internal financial control. Hospital financial control of the internal control of the smooth operation can fundamentally improve the management effect, so that the hospital to achieve scientific management, but also conducive to the hospital to better improve the financial management system and improve, in order to achieve systematic development. During the internal control of hospital financial management, financial management needs to comply with the relevant laws and regulations, management staff should be able to have the appropriate financial skills, so that different departments are able to better financial supervision and cost control. Internal control to a certain extent belongs to the hospital financial management commonly used method, which has a positive impact on improving the level of hospital management, and hospital financial 
management also plays an important role in enhancing its internal control, financial management and internal control are special financial Supervision, economic management, the organic combination of the two to enhance the level of hospital financial management has a positive role, but also to ensure the smooth internal management of the hospital. Therefore, for the hospital management, the first through the establishment of the corresponding internal control system, improve the internal control system to ensure the efficiency of hospital operation; Second, the use of financial management to improve the level of hospital management to prevent the occurrence of risk.

\section{The Measures to Strengthen the Hospital Internal Control and the Externalization Standard Hospital Financial Management}

Enhance the hospital budget management, do the annual budget work. The so-called budget shows that the next phase of the hospital need to spend the work of the assessment of funds, management and budget work will directly reflect the hospital's actual financial management level. Budget and the use of funds difference is too large, whether the balance or deficit will have a negative impact on hospital financial management, financial management work as much as possible to make use of funds and budget to maintain a balance, for the government in health and health policy changes issued by the hospital Financial management process is still using the previous method, it is difficult to produce significant results, the hospital can not blindly through government funding to achieve the balance of budget requirements.

During the budget, the hospital needs to set up a corresponding audit team, and after the budget on the budget, but also need to consider the rationality of the required budget funds. Hospital is not based on work experience, financial management staff needs to combine the actual situation to the medical and pharmaceutical income analysis, so as to get the hospital economic indicators, to make a reasonable scientific judgment, for large amounts of money need to discuss through the leadership team after deciding whether to use.

Conduct a good job of internal control of income and expenditure. Hospital income and expenditure as the main work required during the financial management, through the financial experience in recent years is not difficult to find, many hospitals have different financial loopholes, so to induce a variety of corruption, and the hospital private small Treasury, this illegal phenomenon can be roughly divided into two kinds, first for the hospital finance, fees, managers through the duties to embezzle public funds or misappropriation of public funds; followed by commercial bribery, the hospital all the costs are unified collection, Other staff can not be charged, and the charge staff in the collection of any fees must be issued a corresponding receipt, and after the completion of the charges every day to be able to pay the cash, the documents are checked after the account. Hospital charges work to be able to do a good job of openness and justice, to avoid the actual income of doctors and check the relationship between the phenomenons.

At the level of expenditure, it is necessary to strengthen the budget implementation work, manage the major medical management activities and the Peking Opera decision-making, and need to control the expenses, reduce the consumption and unnecessary expenses. In the use of funds, for small expenses need to pass the approval of the leadership after the entry into force, large expenditure will need to go through the examination and approval authority after the entry into force. All the declaration of funds will need to be in the hospital all the annual budget for the record, for the exact need, does not meet the budget provisions of the capital expenditure will need the hospital administrative departments to determine the actual situation, but also to be able to further strengthen the system of responsible persons to ensure that all Of the funds can be approved to implement the unit. Individuals, to avoid the unreasonable use of funds, waste and so on.

Strengthen the use of science and technology efforts, good computerized financial management. Science and technology as the first productive forces in the development of society today, in all walks of life are playing a more important role in the use of advanced science and technology equipment can also further enhance the hospital financial management, internal control level. The continuous development of electronic computer technology, let it in computerized 
accounting has a significant application. The use of computerized financial systems allows the complex and complex accounting work to proceed smoothly. In the past, financial staff generally faced more statistical data, which would increase the pressure of financial managers to a certain extent, and may also lead to errors due to the large data itself, thereby increasing the probability of loss. Moreover, the application of computer technology in financial management can reduce the workload and reduce unnecessary errors. The use of new technology can also make the data clearer and optimize the work efficiency. It should be noted that the operation of the computer is inseparable from the operation of people, this period may be due to personnel operation errors and increase the loss, so the use of heart technology will have to be able to train the operator to make them better familiar with the Of the software to enhance self-work efficiency and quality of work.

The internal audit system to strengthen supervision and supervision efforts. In the course of the previous audit may be exposed to the hospital financial work in the existence of bad behavior, and the implementation of various policies. Therefore, it is more important to do the internal audit work. In order to improve the level of audit work and the quality of the work, the whole audit process should be able to achieve fair, fair and open requirements. It is best to arrange the work of the third party independent institution to complete the audit. A period of time to publish relevant information, during which all staff, units shall not be disturbed. In addition to internal audit, financial management work should be able to do the supervision and management, for example, in the hospital set up an independent department, the staff is from different departments, the scope of work for the hospital to accept different aspects of financial management complaints.

The establishment of the corresponding internal control financial management system, to help hospitals to carry out relevant work, and to ensure the smooth implementation of relevant policies, so that the hospital intangible assets, tangible assets can meet the complete requirements, so that hospital management benefits to maximize, But also to allow the hospital financial work to meet the safety, real and efficient requirements.

With the development and improvement of the medical market, the hospital is a self-restraint. Many hospitals have begun to implement the target responsibility management, the future work from the previous plan into a budget. However, there are hospitals do not achieve this height, the implementation of a comprehensive budget, many hospitals in the preparation of the annual budget, are combined with the financial budget, combined with the previous financial data, in accordance with the corresponding proportion to implement The Mostly accounting for different items of financial allocations, lack of linkages between budgets and hospital strategic objectives. Only to the hospital budget to be prepared, the lack of level budget, the budget account is not accurate enough. Hospital budget combined with career development tasks plans to prepare, but also an important component of financial management, the preparation of the budget needs to take into account the balance, the principle of balance of payments to carry out. Therefore, the hospital needs to set up a budget management agency and the budget management system to be improved.

Enhance the financial awareness of hospital management and leadership. Financial management work level will fundamentally on the hospital's competitiveness, efficiency, development prospects, and determine the fate of the hospital, the future. At present, some hospital leaders lack the awareness of financial management work, in the management of the hospital, only focus on business, did not realize the importance of financial management, which led to a certain degree of waste of resources, thereby increasing hospital operating costs. Moreover, the hospital financial work has a strong professional the workload is relatively large, involving many aspects of the hospital. Therefore, the need for high-quality financial management staff, but most of the hospital focus on the training of business people, and charges, registered work is carried out by non-professionals, which makes the hospital lack of high quality financial management staff, thus Can not be found in the management of the various problems, long-term development is not conducive to the improvement of hospital competition.

Strengthen the hospital leadership financial awareness, to ensure that financial management staff to do the relevant work. Leadership team through the establishment of a correct scientific sense of management, we can systematically and comprehensively understand the hospital management, 
financial status, and on this basis, analysis and prediction of hospital development prospects, better found in medical activities, identify differences, , And combined with the actual situation of targeted improvement and improvement measures. In order to meet the needs of the new era of development, hospital management and leadership to be able to realize the importance of financial management personnel training, and provide more channels for financial managers to better learn a variety of business knowledge, improve self-business level, So as to meet the needs of the new medical reform situation.

\section{Conclusion:}

With the continuous development of modern medical and health undertakings, the hospital financial management work requires management staff from the previous accounting level into financial management, and only constantly update the concept of self-management work, as much as possible to supplement the corresponding financial management knowledge, Work skills, the use of new scientific methods, do a third party audit, supervision work, to allow the hospital in the fierce competition in the market to occupy a favorable position to create more economic and social benefits, to achieve continuous development.

\section{References}

[1] Zhang Rong. Strengthen the internal control of the hospital to improve the level of financial management [J]. Finance and Accounting, 2017, (03): 256.

[2] Lu Yusheng. Strengthen the hospital internal control standard hospital financial management [J]. Rural Economy and Technology, 2016, (06): $127+129$.

[3] $\mathrm{Xu}$ Weiming. Information management under the conditions of strengthening the hospital financial internal control thinking [J]. China Management Information, 2016, (01): 26-27.

[4] Zhang Qinglin. Improve the overall budget management level to strengthen the hospital financial internal control measures [J]. Finance (Academic Edition), 2015, (24): 276

[5] Liang Guifeng. Strengthen the hospital financial management to improve the internal control of the hospital [J] .Enterprise business assets and finance, 2013, (24): 142

[6] Sun Jing. Improve the overall budget management level to strengthen the hospital financial internal control [J]. China's collective economy, 2013, (35): 89-91

[7] Ren Lichi. The ways to strengthen the internal control of hospital financial management and recommendations [J]. Management observation, 2013, (20): 143.

[8] Shang Junzhen. On the strengthening of hospital internal accounting control and financial management thinking [J] .Automatic business assets and finance, 2012, (08): 136-137

[9] Yang Xianhong. Strengthening the hospital financial management and internal control [J]. China Management Information, 2011, (16): 4-5

[10] $\mathrm{Bu}$ Wubin. Strengthen the hospital financial management and internal control system construction [J]. Finance, 2009, (03): 123. 